\title{
The role of the enrolled nursing auxiliary in a selected health care administration
}

\author{
ET Mabunda, MA Cur student, Department of Advanced Nursing Sciences, UNISA \\ $S$ Booyens, D Litt et Phil, Department of Advanced Nursing Sciences, UNISA
}

\section{Summary}

The purpose of the study was to determine the contribution of nursing auxiliaries towards health care services, against their scope of practice. The sample consisted of nursing auxiliaries in the Gazankulu area in the Northern Transvaal.The findings revealed that nursing auxiliaries are presently an essential component of nursing services rendered in Gazankulu,but that apart from their prescribed role,they are also engaged in activities which should be performed by enrolled and professional nurses,and general assistants.A need for education is apparent for all categories of nursing staff regarding the scope of practice of nursing auxiliaries.

\section{Opsomming}

Die doel van die studie was om die bydrae van verpleeghulpe betreffende die lewering van gesondheidsdienste, met inagneming van hul bestek van praktyk, te bepaal. Die steekproef het uit verpleeghulpe in die Gazankulu-area, in die Noord-Transvaal, bestaan. Die bevindinge het getoon dat verpleeghulpe teenswoordig ' $n$ essensiële komponent in verpleegdienste in Gazankulu uitmaak, maar dat hulle, benewens hul voorgeskrewe rol, 'n velerlei aktiwiteite uitvoer wat eintlik deur ingeskrewe en professionele verpleegkundiges gedoen behoort te word, so wel as deur algemene assistente. 'n Behoefte aan onderrig vir alle kategorieë van verpleegpersoneel betreffende die bestek van praktyk van verpleeghulpe, blyk uit die studie.

\section{Introduction}

Although nursing auxiliaries occupy the lowest position in the nursing posts' hierarchy, they nevertheless provide an indispensable service in health care. Shortage of financial resources in health services in this country leads to the increased utilization of nursing auxiliaries, because money can be saved by not paying high salaries to professional nurses for the performance of duties, which can effectively be performed by enrolled nurses and nursing auxiliaries.

Although nursing auxiliaries play a significant role in health services, there are shortfalls within this category of nurse. According to the Dan Mason Nursing Research Committee (1962:13), there is an uncertainty in the minds of many people regarding the usefulness of the role of the assistant nurse. In his study on the role and function of the various categories of nurse in the health services in the RSA, Rautenbach (1981) indicated that the enrolled nursing auxiliaries were being prepared to perform a role and function for which they were never intended, and that, in his view, they were often being misused.

\section{Purpose of the Study}

The purpose of the study was to determine the contribution of nursing auxilliaries towards the health care of patients in Gazankulu.

\section{Objectives}

The objectives of the study was: to examine the role of the nursing auxiliary against her scope of practice in the Gazankulu-area health services.

- $\quad$ to determine any differences in duties between less and more experienced nursing auxilliaries in the Gazankulu-area.

\section{Research Questions}

The following three research questions were used for the study: 1. Are enrolled nursing auxiliaries necessary in Gazankulu performing duties according to their scope of practice?

2. Are enrolled nursing auxiliaries performing duties that are above/outside their scope of practice?

3. Are there any differences in the duties done by less and more experienced nursing auxiliaries in Gazankulu?

\section{Frame of Reference}

The frame of reference for the study was the prescribed scope of practice of the auxiliary nurse of the previous South African Nursing Council. This is found in Regulation R2598 of 30 November 1984 as amended, namely Regulations relating to the scope of practice of persons who are registered or enrolled under the Nursing Act, No 50, of 1978.

\section{Reasons for the Study}

From a workshop conducted by WHO, Hardie (1983:68) reported that although satisfactory data is available for qualified 
health personnel, in most countries, little information is available about auxiliaries and their work.

The literature revealed mostly descriptions of programme content of the nursing auxiliary and are hence mainly meant to assist the teacher in preparing the auxiliary for her role after completion of her training. Both the public and fellow health personnel tend to look down at nursing auxiliaries and their view as a group of health personnel is that their work, and the contribution they make to the health services, often goes unrecognised and unappreciated.

\section{Target Population}

All the enrolled nursing auxiliaries employed under the Gazankulu Government Service, Department of Health and Social Welfare, and practising within the Elim, Letaba, Malamulele, Nkhensani, Shiluvana and Tintswalo health wards constituted the target population for the study. The target population formed the sample.

\section{Methodology}

The study was descriptive and exploratory in nature.A questionnaire was utilised to obtain the necessary research data. The total group of 493 enrolled nursing auxiliaries within the mentioned six hospitals, health centres ,clinics and visiting points were used as respondents

in order to obtain the most representative view possible. The different questions were organized under the same headings as the stipulations used to describe the scope of practice of the nursing auxiliary by the SANC [Reg.R2598 of 30/11/1984,as amended]. The content validity was furthermore validated by six nursing service managers employed in charge positions of hospitals and clinics in nearby areas.

The instrument was then pilot tested by ten enrolled nursing auxiliaries, randomly selected from one hospital. This resulted in pointing out a number of typing errors to be corrected, and the rephrasing of a number of questions not well understood. The respondents took forty minutes to one hour to complete the questionnaire. This led to the omission of a number of items, in order to have it completed within 30-40 minutes, by a second small group of respondents.

Permission from the Director General, Department of Health and Social Welfare, of the Gazankulu Government Service was obtained for conducting the study. Respondents were ensured of anonymity. The purpose of the study was set out in an accompanying letter to each respondent.

\section{Results of Data Analysis}

Data was analyzed utilizing percentages to portray findings. Furthermore a chi-square-analysis

was done between the two groups of respondents. This was done to see if there were any significant differences in the duties done by those with more years of experience than those with less experience. Please note that where only one percentage figure is given in the discussion, this figure represents the average between the two groups, because no significant differences were detected.

- Respondents were divided as follows:
Those who had from 6 years working experience as enrolled nurses were regarded as the "experienced" group (60\%), while the respondents with the 0-5 years experience, were regarded as the "inexperienced" group.

- The age of the respondents ranged between 30--48 years on average, with $39 \%$ between 30 and 39 years of age.

- Thirty percent (30\%) of the auxiliaries had a standard 10 qualification , and $34 \%$ only had a St. 6 or St. 7 qualification.

- The respondents came from three broad work settings, ie. $10 \%$ from the operating theatre and CSSD; $29 \%$ from community services, and $61 \%$ from hospital wards/units, from areas like medical and surgical wards, paediatric and obstetric wards. - The response rate was $65,3 \%$,i.e. 322 usable questionnaires were returned.

\section{Promotion and maintenance of health}

It was found that some nursing auxiliaries were functioning outside their scope of practice when they administer immunization drugs which was reported to be performed by $29 \%$ of the experienced and $20 \%$ of the inexperienced nursing auxiliaries. (Here one must bear in mind that the high response rate could possibly be related to immunization for tuberculosis, performed while babies are still in obstetric units). Both the experienced and inexperienced group, (51\%),reported that they gave health education talks, discussed patients' conditions with them, their relatives and other health team members and that they were doing home visits to trace defaulters and for follow up purposes.

It was thus found that nursing auxiliaries are providing a valuable service in the improvement and maintenance of health at the primary, secondary and tertiary levels. Some are functioning outside their scope of practice by administering immunization drugs and discussing patients' conditions with patients and relatives.

\section{The provision of family planning information}

The high response rate of $91 \%$ to the items "explain the advantages of family planning" and "explain the different methods of family planning" indicated that nursing auxiliaries are in some way or another involved in both formal and informal health education regarding family planning to clients. The high percentage of positive responses to these items from both groups clearly indicated that both the nurses in the hospitals and the community services perform these activities frequently. This may perhaps be attributed to the fact that the population growth rate of $2.6 \%$ a year is amongst the highest in the world.Family planning was an integral part of the Population Development Programme which was aimed at social upliftment and prevention of overpopulation (Vlok 1991:459461).Much emphasis was thus placed on information regarding family planning.

Nursing auxiliaries are fulfilling an essential health care role regarding provision of family planning information, but function outside their scope of practice when they "prescribe a family planning method to clients".

\section{The execution of a nursing care plan for a patient}

Items under this heading were subdivided into five main areas, which were: 
admission procedures

routine nursing procedures

advanced nursing procedures

recording and reporting

discharge procedures

Regarding the execution of a nursing care plan for a patient,auxiliaries offer a noteworthy contribution by admitting patients,performing routine nursing procedures, with the exception of giving oral medications and administering intramuscular injections, which fall outside their scope of practice (Sorrentiono 1978:11-12 and Nuttelman 1981:8).

On average $80 \%$ of both groups indicated that they assist with patients' admissions by weighing patients, doing urine tests, kitting patients' clothes and valuables, measuring patients' heights and collecting specimens for investigations.

\section{Routine nursing procedures:}

Nursing auxiliaries were also engaged frequently $(66 \%-92 \%)$ by doing simple wound dressings, doing barrier nursing, doing terminal disinfection and sterilizing instruments. It was also reported by $47 \%$ of nursing auxiliaries that they administer oral medicines, while $17 \%$ reported administering intramuscular injections.

\section{Advanced nursing procedures:}

Sixty-one $(61 \%)$ of the respondents indicated that they make observations and perform monitoring of vital signs on unconscious patients. It was also noted that $13 \%$ of the respondents reported giving intravenous injections, while $17 \%$ reported that they are taking blood specimens; $6 \%$ reported that they put up blood transfusions, $9 \%$ reported that they suture wounds, $8 \%$ reported that they applied skin plaster of paris and skin traction, and $43 \%$ reported that they change intercostal drainage bottles.

\section{Recording and reporting:}

Most auxiliaries (85\%) reported changes observed in the patients' condition and $68 \%$ of respondents reported that changes observed in patients, were recorded in the kardex and that $61 \%$ were engaged in writing patient's daily reports.

\section{Discharge procedures:}

Nursing auxiliaries $(90 \%)$ reported that they were actively involved in transferring patients to other wards or clinics/visiting points as well as discharging them homewards. A number of advanced procedures, which nursing auxiliaries are restricted from performing, like giving intravenous injections, applying skin traction, changing intercostal drainage bottles are performed and constitutes a medico-legal risk to the health service where it is performed.

\section{- Promotion and maintenance of the patient's hygiene}

The findings under this headline concurred with the views of Mellish (1990:15), who states that auxiliaries should maintain patients' hygiene and see to their comfort; Parsons (1982:15) who stated that auxiliaries' essential role is to provide basic nursing care in a supportive capacity to the professional nurse; and to that of Sorrentino (1987:11) who stated that the auxiliary is to perform simple and basic nursing functions under the supervision of the professional and enrolled nurse. Between 88-90\% reported performing such tasks as bedbaths, babybaths, mouthwashes, assisting patients to dress and shaving male patients. However tasks such as dampdusting and sluicing of soiled linen, (which should be done by domestic workers), were also reported to be undertaken by $92 \%$ and $90 \%$ respectively.

\section{- Promotion and maintenance of the patient's physical comfort}

The tasks of positioning patients, changing of soiled linen and making beds were reported to be done by $88-90 \%$ of the auxiliaries. Maintaining the physical comfort of patients is a duty of nursing auxiliaries, as pointed out by several authors, like Mackinon (1985:13); Caldwell and Hegner(1992:7), Bregman (1974:4) and Sorrentino (1987:11). In this regard auxiliaries are making a valuable contribution to the patient's comfort, which is an important aspect of patient satisfaction.

\section{- Prevention of physical deformity and other complica- tions in a patient}

The tasks of repositioning bedridden patients, helping them to do passive exercises, treating their back and pressure parts and getting them out of bed were reportedly performed by $90 \%$ of the auxiliaries. Nursing auxiliaries are thus fulfilling an important role in the prevention of pressure sores and disfigurements.

A sizeable number of auxiliaries, working in the maternity wards, (45-60\%), were also facilitating the patients to do the necessary antenatal and post-natal exercises.

\section{- Supervision over and maintenance of an oxygen supply to the patient}

Items relating to this issue included administration of oxygen $(57 \%)$, maintaining a patient on continuous oxygen $(60 \%)$, suctioning of a patient $(50 \%)$, and performing mouthto-mouth rescusita-tion (43\%). If the auxiliaries are properly trained to suction patients and to perform cardio-pulmonary resuscitation, they could be saving lives.

\section{- Monitoring a patient's vital signs}

All the tasks relating to the above, e.g. taking and recording pulse rate, blood pressure, respiration rate, and reporting abnormal readings to seniors, were reportedly performed by $90 \%$ of the auxiliaries, thus making a noteworthy contribution towards nursing care.

\section{- Maintenance of the patient's intake}

All the respondents working in hospital units, reported performing functions like dishing out meals for unit patients, feeding helpless patients, feeding babies, preparing oral rehydration fluids, recording intake and ensuring sufficient drinking water or other fluids for patients. It was however discovered that $16 \%$ of the respondents reported inserting naso-gastric tubes, while $21 \%$ stated that they put up intravenous infusions, a task which definitely falls outside their scope of practice (Stevenson 1987:122-124).

\section{- Maintenance of elimination in a patient}

All the respondents working in hospital units reported that they give bedpans and urinals to patients, empty urine collecting bags, observe stools, vomitus and sputum, report observations and record outputs. There were however $15 \%$ of the respondents who reported that they inserted female bladder catheters and $11 \%$ who stated that they performed male catheterization. Sorrentino (1987:12) 
lists the insertion of bladder catheters amongst those functions which may never be performed by nursing auxiliaries.Nursing auxiliaries help to make patients feel comfortable, by attending to patients' elimination needs. They also contribute to nursing care by observing stools, vomitus and sputum, report observations and recording output.

- Promotion of communication with a patient during care Nursing procedures and hospital routine were reportedly explained to patients by $58 \%$ of the respondents. Patients are eased in their role as hospital inhabitants by auxiliaries, explaining hospital routines and nursing procedures

- Preparation of individuals and groups for undergoing diagnostic procedures and therapeutic acts.

Although $85 \%$ of the respondents reported preparing patients for $x$-rays, only $45 \%$ reported

preparing patients for a barium meal, or enema; only $40 \%$ reported preparing patients for an ultrasound investigation, and only $24 \%$ reported preparing patients for an intravenous pyelogram.

- Preparation for, and assistance during surgical procedures under anaesthetic

It was disconcerting to find that $70 \%$ of the respondents reported explaining their operation to patients, and $68 \%$ overseeing the signing of the consent form for operation, $86 \%$ reporting transporting patients to theatre (a non-nursing duty), and $83 \%$ receiving patients back from theatre (the responsibility of more senior nursing staff).

\section{- Care of a dying patient and a recently deceased patient}

These functions, which are within the scope of the practice of nursing auxiliaries, such as laying out of the dead and identifying a corpse for removal from the mortuary were performed as portrayed by the response rates. Functions such as remaining with a dying patient $(61 \%)$, and giving the death message to relatives $(24 \%)$, can however not be expected to be performed by nursing auxiliaries.

\section{- Routine ward administration}

The list of non-nursing duties which were very frequently (5393\%) performed by the auxiliaries, included counting dirty linen to the laundry and receiving clean linen from the laundry, daily ordering of meals for patients in the unit, doing the inventory, collecting medicines from the pharmacy, taking specimens to the laboratory, collecting supplies, e.g. stationary from stores, and taking patients to different treatment areas, e.g. physiotherapy.

\footnotetext{
- Significant differences in the duties done by experienced and less experienced groups

Most of the items did not show a significant difference between the experienced and the inexperienced nursing auxiliaries. Significant differences on the $0.05 \%$ level were noted on the following items/duties:

* administering of immunization drugs

$\star \quad$ prescribing a family planning method to clients

$\star \quad$ collecting specimens for investigations

$\star \quad$ giving intramuscular injections

$\star \quad$ doing baby baths

$\star \quad$ shaving male patients

$\star \quad$ performing post natal exercises

$\star \quad$ suctioning of a patient.
}

\section{Other Duties Performed By Auxiliaries}

The respondents also listed numerous duties which they perform, but which, according to their view, should actually be done by general domestic assistants.

\section{- Maintenance of environmental hygiene}

The following tasks were listed:

- cleaning/scrubbing/sweeping floors, the linen room, the kitchen, nurse's home, the kitroom.

- cleaning of bedpans, urinals, toilets, the sluice room and the refrigerator.

- washing windows, cupboards, lockers, chairs and bandages.

\section{- Linen services}

The following were listed:

- sluicing and counting of soiled linen.

- receiving clean linen from the laundry and packing it in the linen room.

- washing and ironing linen.

\section{Catering Services}

A number of duties which the nurse auxiliaries would like to be relieved from included mostly nursing duties, such as feeding patients, but the following were also recorded: collecting baby feeds from the kitchen, cooking for nurses and patients and preparing tea for doctors and nurses in the operating theatre.

\section{Messenger Services}

All the activities listed are purely messenger services which can safely and effectively be carried out by porters or general assistants, e.g. collecting supplies from stores, pharmacy and stationary, wheeling patients and corpses to their different destinations, taking specimens to and collecting results from the laboratory.

\section{Other Non-specified Activities}

These included such activities as burning things in the incinerator, powdering of gloves, making ice packs for use in physiotherapy and washing dirty instruments. Duties which were not listed in the questionnaire were also listed by the respondents and included such activities as collecting patients from a "call-out", transporting patients to the bus station, taking of malaria smears, blood specimens, removing of plaster of paris, taking report when coming on duty, giving report to the next shift, giving physiotherapy treatment, compiling statistics, suturing of a corpse after post-mortem, sorting out patients for treatment.

\section{Conclusions}

The results of this study led to the following conclusions:

1 The South African Nursing Council provides rules and regulations regarding the provision of nursing services within a broad framework of the scope of practice of the various categories of nurse. Nursing auxiliaries are found to perform a wide variety of duties which are not confined to their scope of practice as prescribed by the SANC. A clear discrepancy exists between limitations placed on their duties and their 
actual practice. It is recommended that the SANC should list the duties which nursing auxiliaries should never perform, except in emergencies.

2 Nursing auxiliaries appear to be incorrectly utilized by professional and enrolled nurses who delegate a number of non-nursing domestic duties to them as well as duties above/ outside their scope of practice. It is recommended that regular in-service-education sessions be given about the scope of practice not only to nursing auxiliaries themselves, but also to professional and enrolled nurses who act as supervisors to nursing auxiliaries. The provision of sufficient numbers of domestic staff would perhaps alleviate the burden of domestic duties often delegated to auxiliaries.

3 Where nursing auxiliaries are utilized to monitor patients' vital signs, to the extent shown in this study it is extremely important that the senior nursing personnel should do regular rounds and check ups, to make sure that what is recorded does indeed portray the state of illness of the patient correctly.

4 Nursing auxiliaries are currently an important component of nursing services in Gazankulu, as evidenced by the different aspects of nursing care which they perform in their work situation.

\section{Final Comments}

The research questions posed for this study were thus answered as follows:

1 Enrolled nursing auxiliaries are currently necessary, and seemingly essential, for the provision of health care services in Gazankulu.

2 Enrolled nursing auxiliaries are performing a number of duties which are outside or above their scope of practice which is currently still in place and described by Regulation 2598 of 30/ 11/1984 of the South African Nursing Council, as amended.

3 There were only eight items which showed a significant difference in the responses between the experienced and the lesser experienced group of auxiliaries. These were mentioned in the description of the results of the data analysis

\section{References}

BREGMAN, MS 1974: Assisting the health team: an introduction for the nurse assistant. Saint Louis: Mosby.

CALDWELL, E \& HEGNER, BR 1992: Nursing assistant: a nursing process approach. 6th edition. Albany: Delmar.

DAN MASON NURSING RESEARCH COMMITTEE of the National Florence Nightingale Memorial Committee of Great Britain and Northern Ireland, 1962. London.

HARDIE, M 1983: A case of professional neglect. Nursing Times. 79(28):68-69.

MACKINON, C 1985: The nursing assistant in South Africa. Pretoria: Sigma Press.

MELLISH, JM 1990: A basic history of nursing. 2nd edition. Durban: Butterworths.

NUTTELMAN, DG 1991: Managing a nursing assistant training program. Albany: Delmar.

PARSONS, R 1982: Some aspects of the report on the role and function of the enrolled nursing aid in New South Wales. The Lamp. 39(1):13-27.

RAUTENBACH, CT 1981: A definition of the role and function of various categories of nursing personnel in the Republic of South Africa and an analysis of the effectiveness to fulfil these functions. Doctoral theses. Port Elizabeth: University of Port Elizabeth.

SANC 1972: Guidelines for the certificate for enrolment as a nursing assistant (based on Regulation R1834, 1972), Pretoria: SANC.

SORRENTINO, SA 1987: Mosby's textbook for nursing assistants, 2nd edition. St Louis: Mosby.

SOUTH AFRICA 1984: Regulations relating to the scope of practice of persons who are registered or enrolled under the Nursing Act. 1978, Regulation R2598. in terms of the Nursing Act. 1978 (Act No. 50 of 1978, as amended). Pretoria: Government Printer.

STEVENSON, JC 1987: The nursing assistant's guide. Cape Town: Juta. 